\title{
XIX - XX. YÜZYILLARDA NAHÇIVAN EDEBIYYATINDA DOĞU ETKİLERİ
}

\author{
Nergiz İSMAYILOOA*
}

\begin{abstract}
$\ddot{O} z$
Makalede XIX - XX. yüzyıllar Nahçıvan edebî ortamının sanatçıları olan Celil Memmedguluzade, Mehmet Sait Ordubadi ve Hüseyn Cavit'in bir sıra eserlerinde yer alan Doğu etkileri ve bunu yaratan nedenlerden bahsedilmiştir. Nahçıvan ortamına Doğunun etkileri birçok alanda hissedilmiştir. Bu makalede üç yazarın eserlerindeki Doğu edebiyatı etkisini ele alınarak XIX - XX. yüzyıllarda Nahçıvan edebî ortamında hissedilen Doğu etkilerininim edebiyatımızda yarattığı farklılık ve bu etkilerin çizdiği tarihi yol anlatılmıștır. Belirtelim ki, Nahçıvan edebî ortamının sanatçıları olan Celil Memmedguluzade, Mehmet Sait Ordubadi ve Hüseyn Cavit o dönem Nahçıvan edebiyatının önemli isimleri olmaları dışında, birçok ilklere imza atan dünyevi mevzulara dikkat çeken yazarlardır. Batı edebiyatına eğilimin arttığı bir zamanda, Doğu edebiyatına saygının izleri hâlen duruyordu. Nahçıvan edebî ortamında yaratılan edebiyatta Doğu konusu, Doğu'yu öğrenmek, tebliğ etmek geniş kapsamda yer almıştır. Doğu'ya ilgi, Doğu'yu terennüm etmek XIX - XX. yüzylllarda önceki dönemlerle mukayesede azalsa da, belli grup sanatçıların yaratıcıllğıında bu motif güçlüydü. Bu dönemde yaşayan Nahçıvanlı sanatçıların eserlerinde Doğu motifi farklı şekilde anlatılmaktadır. Makalede Nahçıvanlı yazarların Doğu edebiyatından etkilenseler de yeni mevzulu millî edebiyat yaratma çabalarından da bahsedilmiştir. Bu sanatkârların yaratıcılığında yer alan Doğu mevzusu hakkında somut edebî - bedii bulgulara dayalı belirli bilimsel neticeler elde edilmiştir.
\end{abstract}

Anahtar Sözcükler: Nahçıvan, doğu, edebiyat, edebî ortam, XIX - XX. yüzyllar.

\section{THE EAST INFLUENCES TO LITERATURE IN NAKHCHIVAN DURING THE XIX-XX. CENTURIES}

\begin{abstract}
The article deals with the East influences and its reasons in Jalil Mammadguluzada's, Mammad Said Ordubadi`s and Huseyn Javid's works the craftsmans of XIX - XX. centuries of Nakhchivan literary environment. The East to Nakhchivan environment is felt in many areas. In this article the author has got three craftsmen's work where the influences of East literature is felt much. The difference in Nakhchivan literary environment because of the influences of East literature during the XIX - XX centuries and its historical way is investigated. We must note that the craftsmen as Jalil Mammadguluzada, Mammad Said Ordubadi and Huseyn Javid is not only the most prominent persons of Nakhchivan literary environment but also the writers who brought some more innovation in the worldly subjects. The respect to East literature was exist during the period when there was a direction to West literature. East topic, learning the East, to propagate the East was widely spread in Nakhchivan literary environment. Attention to East, making sweat the East in the XIX - XX centuries was fewer than previous period. But this motive was strong in the creative work of a group of craftsmen. East motive is explained differ in the craftsmen of Nakhchivan in who lived and worked in this period. In the article the author tries to explain
\end{abstract}

\footnotetext{
*Arș. Gör.; Nahçıvan Milli Bilimler Akademisi, nergiz.ismayilova@ hotmail.com.
} 
that though craftsmen of Nakhchivan influences from East literature but all of them tried to create national literature. Result of the investigation the author got some more new facts in the creative work of these craftsmen dealt with East topic.

Keywords: Nakhchivan, east, literature, literary environment, XIX - XX. centuries.

\section{Giriş:}

XIX - XX. yüzyıllar Azerbaycan edebiyatı tarihî için özel bir önem taşımaktadır. Bu dönemde hem dünya edebiyatında, hem de Azerbaycan edebiyatında ilginç fikirler ortaya atılmış, bu doğrultuda farklı edebî yaklaşımlar oluşmuştur. O dönemin edebiyatı başarılı gelişme dönemi geçirmekle birlikte karışıklıkları da bünyesinde barındırmaktadır. Dünyaya entegre, dünya edebiyatı ile sentez, dünya edebiyatı ötesinde millî edebiyat oluşturma girişimleri bu dönem edebiyatının temel prensiplerinden biri olarak önem taşımaktadır. XIX. yüzyılın sonu XX. yüzyılın başlarında Nahçıvan Azerbaycan bilimine ve maarifine büyük katkılarda bulunmuştur. Azerbaycan'da tezahür eden millî aydınlanma hareketi Nahçıvan'da da kendini göstermeye başlamıştır. Sosyal ekonomik, sosyokültürel yenilikler; ilerici, demokratik aydınlar tabakasının oluşumu için verimli bir zemin yaratmış, yeni tip medeni-maarif ocaklarının düzenlenmesi sonucunda laik bilimler öğretimi çoğalmış, öğretmen ve öğrencilerin sayısı giderek artmaya başlamıştır. Batı literatürüne eğilimin arttığı bir zamanda, Doğu edebiyatına saygının izleri hâlen duruyordu. Bu dönemde yaşayan Nahçıvanlı sanatçıların eserlerinde Doğu motifi farklı şekilde anlatılmaktadır.

Uzun süre dış etkenlerden ve yabancı ülkelerin siyaset, tarih ve edebiyatından etkilenen edebiyatımız tüm bu etkenlere rağmen, birçok siyasi yasakları atlatarak, halkın parlak geleceği arzusuyla durmadan mücadele etmiştir.

Bu bakımdan yirminci yüzyılın başlarında ortaya çıkan "Molla Nasreddin" dergisi edebiyatımızı yeni bir yöne yöneltti. Nahçıvan edebî ortamında bu dönem edebiyatının oluşumu ve gelişiminde Eyneli Bey Sultanov, Mirze Celil, Eliqulu Qemküsar, Qurbaneli Şerifzade ve başkalarının hizmetleri unutulamaz. Nahçıvan ortamında şekillenmeye başlayan Batı tefekkürü, Batı meyilleri XIX. yüzyılın sonlarına doğru daha da gelişmiş bir şekilde tezahür ediyordu. Biz bu dönemde yazıp yaratan sanatçıların eserlerinde bunu görüyoruz. Tarihsel olarak bir Doğu ülkesi olarak gelişen ve son bin y1lda İslam kültürünü ve manevi değerlerini benimsemiş olan Kuzey Azerbaycan XIX. yüzyıldan başlayarak Rusya'nın bünyesinde yeni kültürel değerler sistemi ile yoğun ilişkiye girmek zorunda kalmıştır. Rusya aracılığıyla gelişmiş Avrupa sosyal, siyasi fikrinin ve aydınlanma düşüncelerinin Azerbaycan'a geçmesi Doğu ve Batı değerler sisteminin bu ülkede birbirine kavuşması için zemin oluşturdu. Bu durum kendini her alanda göstermeye başladı. 
XIX. yüzyılda edebiyatın daha çok Doğu yaratıcılık tipine meyil gösteren bir kolu edebî meclislerde oluşuyordu. Burada milletini seven, Batıyı öğrense de, millî edebiyatın oluşumu için çaba sarf eden insanlar toplanıyordu. Onlar bu tür meclislerde eski ve yeni edebî örnekleri okuyor ve tartışıyorlardı. Burada Doğu edebiyatına, kültürüne merakı olan, Doğu edebiyatına meyil eden sanatçılar vardı.

Qubadak1 “Gülistan”, Ordubaddakı "Encümeni-şüera” (Şairler meclisi), Lenkerandak1 "Fövcül-füsaha" (Güzel konuşanlar), Şamaxıdakı "Beytüs-Safa” (Sefanın evi), Bakü’deki "Mecmeüş-şüera" (Şairler toplusu), Gencedeki (sonraları Tiflis’te) "Divani-hikmet”, Şuşadakı "Meclisi-üns", "Meclisi - fəramuşan" (Unudulmuşlar meclisi) ve sair gibi edebî ocaklar ortamın oluşmasında önemli rol oynamışlar.

Bu meclislerde Doğu ve Batı edebiyat örnekleri okunuyor ve burada toplanan insanlar dünya edebiyatıyla bu yolla tanışıorlardı.

Antik kaynaklarda Doğu'nun Batı'ya kültürel etkisi ile ilgili yeterli bilgiler mevcuttur: "İlginçtir ki, eski Yunan mitolojisinde bazı Yunan kabilelerinin ve nesillerinin kökeni eski Doğu'ya bağlanıyor. Yunan edebiyatında bazı epik motifler de Doğu ile bağlantılıdır. Bu açıdan 'Odysseia' da Kiklop - Polifem hakkındaki hikâye ilginçtir. Tek gözlü (tepegöz) dev yaratıklar hakkında rivayetler dünya halklarının, özellikle eski Türklerin sözlü edebiyatında olan süjetlerdir" (Nağıyev, 2004: 3-4).

$\mathrm{Bu}$ tür örneklere biz R. Babayevin Babayev. R. "Azerbaycan Folklorunun Regional hususları" (Nahçıvan folkoru materyalleri) adlı araştırmasında da rastlıyoruz: "Kırgızlar" tek gözlü yaratığı "Malgün, yani Melun, qaqauzlar ise Denegoz adlandırırlar. Yunan, Hint ve diğer kaynaklarda onunla ilgili ilginç bilgiler var. Azerbaycan folklorunda Tepegöz ise daha ilginçtir" (Babayev, 2008: 46).

"Genel olarak XIX. yüzyılın edebiyatı, Azerbaycan edebiyatının yeni yüksek aşaması sayılan XX. yüzyıl edebiyatına geçiş için sağlam bir zemin hazırlamıştır. Mehemmedağa Şahtahtılı'nın kültür kavramı ve bundan doğan vatandaşlık nitelikleri "Doğu - Rus" gazetesinde yayınlanan "Her gün biraz" dizi makalesinde de kendi ifadesini bulmuştur. O, Doğu'nun hayatını anlatırken öncelikle gelişimi önemli bir faktör olarak görür. Avrupalıların tüm başarıları ve yeni kültürleri araştırarak elde ettiklerini söyleyerek bunu Müslümanlara örnek gösteriyorlardı. Aynı zamanda, gelişme konuşurken kadınların toplumdaki rolüne özel önem veriyor. Avrupa ve Amerika kadınları ile Müslüman kadınları arasındaki farkın Doğu'nun zararına işlediğini söylüyorlardı" (İskender, 2011: 41). 
Kadın özgürlügü sloganı ile dikkat çeken sanatçılardan olan Eyneli Bey Sultanov ve Celil Memmedquluzade kadınların özgürlügünü, gelişimini ilimde, eğitimde görüyorlardı.

Eyneli Bey Sultanov makalelerinde Kafkasya ve Doğu halklarının çıkarlarını savunmuştur. O “Teze pir” hikâyesinin öncesinde Hafizden bir alıntı yapmıştır: "pərdə zi rindani-mest purs" (s. 35), (Perdenin arkasındaki sırrı sarhoşlara sor). Bu hikâyede dini anlamadan Müslüman olduklarını iddia edenlerin cahilliğinden ve onların komik taraflarından bahsediliyor. Hikâyede eşeğin mezarının halka "salih, mü’min kişinin mezarı" gibi gösterilip, mezarın üzerinde türbe yapan dolandırıcılar eleştiriliyor.

Azerbaycan klasikleri ile birlikte, Doğu ve Batı'nın büyük sanatkârlarını, büyük düşünürlerini, öğrenciyken okuyup öğrenmeye başlayan Mirze Celil ise bu işe 80 - 90 yıllarında başlamıştır. Dünya kültürü genç yazarın teşekkülüne yardım eden bir faktör, fikir hazinesi olsa da, ona göre, her bir millî kültürün kendi değeri ve güzelliği vardır.

C. Memmedquluzade "Danabaş kəndinin əhvalatları" eserinde eski Yunan filozofu Sokrat'dan alıntı yapmıştır. Aynı eserde hem de "Cameyi - Obbasi" eserinden bahseden yazar gazeteci Halil'in diliyle o zaman okunan eserlere bu yolla fikir bildirmiştir. Görüldüğü gibi, sonraki dönemde Azerbaycan'ın okul ve medreselerinde Şirazlı Sadi’nin "Gülistan", "Bostan" eserleri, Fuzuli'nin “Divanı”, “Tarih-i Nadir”, “Cameyi - Obbasi” gibi kitaplar derslik ve ders kitapları gibi yaygın olarak kullanılmıştır. Bu kitaplar öğrencilerin bilgi ve yaş düzeyine uygun olmasa da dersliklerin ilk örnekleri olması açısından değerlidir. C. Memmedquluzade'nin başkanlık ettiği "Molla Nasreddin" edebî mektebinin temsilcilerinin eserlerinde Doğu etkisi, Doğu konusu güncellenmiştir.

Molla Nesreddinin adı Doğu halklarına tanıdık bir isimdir. Yüzyıllarca farklı topluluklarda, kişilerin birbirleri ile sohbetlerinde sık sık duyulan Molla Nasreddin fikraları ağızdan ağıza geçmiş, söylenen öykülere, söylenen fikirlere önem katmıştır (Mollayev, 1983: 43).

Doğu etkisinin temelinde gelişen Nahçıan edebî ortamı gittikçe Batı edebiyatı ile sentez ediliyordu. Bu edebiyat kavşağında oluşan yeni edebî ortam için yeni nefesti. Mehmet Said Ordubadi'nin eserlerinde bu sentez daha ön planda gözüküyor.

“Dumanlı Tebriz" tarihî romanı ise Güney Azerbaycan'da ulusal özgürlük hareketinin tarihini sistemli yansıtan romanlardandır. Bu romanda Settar Han hareketi tasvir edilmiştir. Romanda Settar Han, Bağır Han gibi kahramanların halkın özgürlüğü yolunda gösterdiği kahramanlıklar anlatılmıştır. “Azerbaycan'da birkaç nesil Serdari-millî Settar Hanı kudretli bir kumandan olarak tarihten çok "Dumanlı Tebriz" eserinden tanımıştır” (Ordubadi, 1985: 14). 
Doğu ve Batı'nın sentezi şeklinde yazılan bu roman değerli bir yapıttır. Eserde yazarın Doğu'ya ve Batı'ya bakış açısı çeşitli karakterlerin dili ile sergilenmektedir. "Dumanlı Tebriz" romanında da Batı'nın Doğu'ya, Doğu'nun da Batı'ya yaklaşımı anlatılmıştır. Eserde “Vahşi Doğuya” kültür armağan ettiğini düşünen, Doğuyu medenileştirmek isteyen Rus, Alman, Türk, İngiliz halklarının iç yüzü ustalıkla tasvir edilmiştir. Eserin çeşitli bölümlerinde Ordubadi Doğu ve Batı'nın kıyaslamasını yapmıştır. Doğunun maddi zenginliklerini anlatan yazar bazen de Doğu'nun düşüncesinde yer alan geriliği eleştiriyor. “Doğu'nun zengini bile Batı'nın zenginiyle ile kıyaslanamaz" gibi ifadeler bu fikri kanıtlıyor. Eser Doğu'da gözüken fanatik ve cahil ortamın sanatsal ve siyasi manzarasını oluşturuyor: Dinini iyi bilmeyen doğuluları, molla kılığındaki Rus ve Batı casusları aldatmıştır. Doğuluların yaşadığı evleri anlatan yazarın bu kayıtları ilgi çekiyor: "Genellikle, Tebriz evleri Fransızların neşe ve zevkine uygun bir tarzda tasarlanmıştır. Tebriz evlerinde çıplak melek resimlerine rastlıyoruz" (Ordubadi, 1985: 82) diyen yazar bu usulle Doğu'daki Batı etkisine dikkat çekmek istemiştir. Ancak bunun dışında Doğu'da Batı etkisini anlatan bu küçük hususlar hariç, Doğu'da Batılaşmak havası hissedilmiyor.

Ordubadi eserinde farklı fikirler sergilemiştir. Doğu kadınının güzelliğini yüceltse de "Özellikle gözlerinden gülmek ve bakışında oynamak sadece Tebriz kadınlarına ait bir özelliktir" (Ordubadi, 1985: 84) dese de, eserde esas karakter olarak batılı kadın seçilmiştir. Edip romanda Saib, Sadi, Hayyam, Hafız, Rudeki, Fuzuli, Hakani, Firdevsi gibi Doğu'nun ünlü yazarlarını da hatırlamıştır.

Doğu'daki gelişmelerin her alanına dikkat çekilen "Kılıç ve Kalem” eseri de bu açıdan değerlidir. Eserde yazar Firdevsi'den bahsetmiş, hatta bazen onun belli görüşlerine katılmadığını da belirtmiştir. Fakat buna rağmen Ordubadi Doğu'nun dahi sanatçısını büyük saygıyla anmıştır. Nahçıvan edebî ortamında yaratılan edebiyatta Doğu konusu, Doğu'yu öğrenmek, tebliğ etmek geniş kapsamda yer almıştır. Doğu'ya ilgi, Doğu'yu terennüm etmek XIX - XX. yüzyıllarda önceki dönemlerle mukayese edildiğinde azalsa da belli grup sanatçının yaratıcıllğında bu motif güçlüydü.

Kaynaklarda anlatılan Qemküsar da Doğu ve Azerbaycan edebiyatını derinden benimsemiştir. Örneğin, araştırmacı İman Ceferov kendisinin “Ә. Qəmküsar yaratıcılığında Şərq - Türk Đdəbiyyatına Münasibətin Tənqidi - Realist Prinsipləri” adlı makalesinde yazmıştır: "Eliqulu Qemküsarın Doğu - Türk edebiyatı ile bağlılığında aşağıdaki hususlar daha çok ilgi çekmektedir: 
1. Klasik Doğu şiir şekilleri,

2. Doğu edebiyatı tarihinde önemli yer tutan ünlü yazarların veya karakterlerin göz önüne getirilme çabası,

3. Klasik Doğu - Türk edebiyatına saygı,

4. Çağdaş Türk yazarlarının yaratıcılığına eleştiri (Oliqulu, 2001: 30).

Hüseyin Cavit ise Doğu konusunu eserlerinde kendine özgü bir şekilde anlatmıştır. Malumdur ki, "Şeyh Sinan” Azerbaycan edebiyatında ilk manzum tarihî facia yapıtı olarak biliniyor ve bu konunun tarihî veya efsanevi olup olmaması ise tartışılır bir konudur.

"Cavidname" yazarı Azer Turan yazıyor: "Şeyh Sinan" "Dünya edebiyatında tasavvuftaki kavramların toplu hâlinde uygulandığı ilk eserdir." (İskender, 1996: 50) bu satırlar çok büyük ve derindir, Cavit dehası hakkında akıcı bilgidir.

Bir hususa da dikkat edelim: "Şeyh Sinan"a Sinan "Piri - mürşid" diye hitap edilip dervişte ilahi nuru görmüştür, ayrıca Humarı görünce, "Lailahe illallah" diye kelime-i şehadet getiriyor, ona ilahi bir varlık olarak secde yapar, onu "nuri-hak" adlandırır:

Evet, en muhterem, asil insan

Hele dursun kemal1, marifeti,

Onda var sanki evliya sıfatı.

Hüseyin Cavit "Şeyh Sinan” da "Kur'an” dan bazı cümleler kullanmıştır. Örneğin, "Her üçü (büyük bir hayret içinde ahengi - mahsus ile) "inna - lillahi ve inna - ileyhi raciun" (Cavit, 2005: 194).

Gerçek şu ki, H. Cavit bu eserinde romantik faciada "ilahi aşk" kavramına dikkat çekiyor. Eserin sonunda Şeyh Sinan Humar'ın elinden tutup “Ya Allah!” Diyerek uçuruma atlıyor. "Doğru olana, gel uçalım!" diyor Şeyh Sinan. Okur bu uçurumdaki yüksekliği manevi anlamının farkındadır.

"Kur'an” aracılığıyla öğrenilen cennetin eski Türk dilindeki eşanlamlı manası uçmak olarak gösteriliyor. Dervişin haber verdiği ve herkesin şahit olduğu gibi Şeyh Sinan'la Humar'ın gökyüzünde birer melek olarak kalktığı kısım romantizm edebî metodunun imkânları çerçevesinde incelemek yeterli değildir, burada göğe dönen Türkoğlu Sinan var, Tanrı sevgisinin karşılığında cennetle müjdelenmiş Sinan vardır (Cavit, 2005: 77).

Böylece anlaşılıyor ki, H. Cavit'in ilahi aşk sahibi Şeyh Sinan'1 Tanrı'ya kavuşma mekânı olarak cenneti seçmiştir (16). Hüseyin Cavit'in "Şeyh Sinan faciası" kendi klasik manasıyla Feridüddin Attar'ın eserindeki Sinan hikâyesiyle, hemen hemen, aynı tasavvuf ortamında cereyan ediyor. Her iki eserin paralel araştırılması sırasında anlaşılıyor ki, Attar ve 
Cavit'te, neredeyse, sujet, metin ve semboller bile aynıdır, ama buna rağmen farklar önemsiz olduğu kadar da çok ciddi.

"Şeyh Sinan" eserinde "Hakikat isterim, sadece gerçek!" diyen Derviş buna ulaşmanın yolunu şüphede görüyor. Zira Cavit'in dervişi bir sufi şeyhinden daha çok, kalp konusunda uzmanlaşmış Batı divanesidir bir Şopenhauer ve ya Nietzsche olduğunu söyleyebiliriz.

Ama daha somut karş1laştırmalar gösteriyor ki, o, bir Nietzsche. Burada Nietzsche'nin düşüncesi onun "Böyle Buyurdu Zerdüşt" eserindeki ihtiyar karakterine benziyor. Cavit'te ihtiyar, nurani derviş ağaçlık araziden Şeyh Sinan'ın karşısına çıkıyor. Nietzsche'nin eserindeki nurani ihtiyar ormanda Zerdüşt'ün karşısına çıkıp, ona insanlardan uzak durmasını tavsiye ediyor: Şimdi sadece Allah'ı seviyorum. İnsanları sevmiyorum artık. İnsan benim nazarımda eksik, tamamlanmamış mahlûktur, diyor (Nietzsche, 2012: 49).

Bazen Cavit'in yolu Nietzsche'den ayrılır ve yeniden F. Attar'la birleşir. Cavit'in “İblis" faciası ise Doğu'nun hayır ve şer düşüncesinin en güzel şekilde anlatan bir eserdir. En yaygın bakışlardan biri Hayrın da, Şerrin de, Allah'ın da, İblis'in de insanın kendi kalbinde, kendi içerisinde arınma çabasıdır.

Cavit sanatında Doğu konusu çeşitli açılardan ele alınmaktadır. O bazen Doğu'nun dahi filozofundan bahsediyor, bazense Doğu'nun yiğit kahramanlarından. Onun eski Doğu klasikleri arasında daha çok sevdiği, sanatına ve kişiliğine saygı ettiği kişilerden biri de Ömer Hayyam'dır. O, Hayyam'ın sanat1 ile birlikte, düşünürlüğü ile de ilgilenmiş, bunu eserinde yüksek ustalıkla göstermiştir. Cavit'in eserlerinde felsefe tarihinde önemli rol oynayan birçok filozofların, seçkin düşünürlerin hizmetlerine de değer verilir. İbni Sina'nın felsefe tarihinde ne kadar önemli yer tutması ve yarattığı eserlerin değeri şöyle yorumlanmaktadır:

İbni Sinan'ı eşitdinsə, oku,

İşte Doğu'nun o büyük filozofu

Bak, yaratmış ne büyük harikalar,

Bir deha nur ki, daim parlar.

İşte, bu "Mantık", bu da "Kanuni-şifa"

Bunların kadrini anlar ürefa (Cavit, 2005: 94).

Cavit'in "Peygamber" dramının Doğuya bağlılı̆̆ eseri tarihî gerçekleri temsil ediyor. Eser "Biset", "Davet", "Hicret", "Nusret" olarak adlandırılan dört kısma bölünmüştür ki, bu da Muhammed'in peygamber olarak seçilmesi anından başlamış, sonra İslam dinin zafer çalması, yayılması ve genişlemesi dönemine kadarki aşamaları kapsar. 
Dram tarihî olgularla zengindir ve gerçekleri içerir, ayrıca yazar tarafından tarihî kanıtlara objektif tutum sergilenmekle beraber konuya ciddiyetle yaklaşılmıştır. Eserin "Biset" kısmı adından da anlaşılacağı gibi, Hazreti Muhammed'in hayatının, peygamberliğin gelmesi dönemini kapsıyor. Peygamber'in kutsal ruhunun Allah arayışı, onu anlamak isteği, "siyah çarşafi” yırtıp hüsnü mutlaka kavuşma arzusu birinci kısımda kendi ifadesini bulmuştur.

Cavit "Seyavuş" eseri ile Doğu'nun büyük sanatkârı Firdevsi'ye olan saygısını sergiledi. Firdevsi ve onun Şehname eseriyle bizim edebiyatımız arasında büyük bir ilişki vardır. Bu ilişski dört şekilde meydana çıkmaktadır: 1) Firdevsi kahramanlarının halk yaratıcılığına etkisi, 2) Yazarların Firdevsi'ye yaklaşımı, 3) "Şehname" den çeşitli parçaların tercüme edilmesi, 4) Eserlerde Firdevsi üslubunun taklit edilmesi” (İskender, 2011: 19).

Nahçıvan Azerbaycan'ın eski kültür merkezlerinden biri olmuştur. Ünlü şairler, yazarlar, bilim ve kültür adamlarının vatanı olan bu toprakta oldukça zengin edebî ortam oluşmuş buradaki edebiyatta tarih, sanat, psikoloji, pedagoji, coğrafi, siyaset bilimi, dil bilimi ve başka bilimlerin izleri vardır.

Sonuç olarak söyleyebiliriz ki, Nahçıvan edebî ortamında her zaman eski Doğu'ya özel rağbet ve saygı olmuştur. Son dönemlerde genç yazarların eserlerinde yer alan Doğu tarzını yansıtan örnekler de bunun en güzel örneğidir.

\section{Kaynaklar:}

BABAYEV, R. (2008). Azerbaycan Folklorunun Regional Hususları. (Nahçıvan Folkoru Materyalleri) Filol. Üzrə Felsefə. Dok Dis, Naxçıvan.

CAVID, H. (2005). Eserleri, Beş cildde IV. cild. Bakı: Lider.

CAVID, H. (2005). Eserleri. Beş cildde III. cild. Bakı: Lider.

CAVID, H. (2005). Eserleri. Beş cildde II. cild. Bakı: Lider.

OLIQULU, (2001). Q Taleyi va Sanatı. Bakı: Elm ve Tahsil.

OLIYEV, K. (2013). Edebiyat Tarihine Bir Baklş. Bakı: Folklor İnstitutu.

XӘLILOV, S. (1996). Cavid falsefesi (1. Kitab: “íblis” də Felsefi Motifler). Bakı: Qanun.

İSKENDER, A. (2011). Yüzyılın Şairi (Üçüncü Kitab) Hüseyn Cavid Azerbaycan Sovetler Edebi Tenqidinde, Bakı: Müallim.

MOLLAYEV, İ. (1983). Naxçıvanda MSSR-Də Maarifin Inkişafi. Bakı: Bilik cemiyyəti.

NAĞIYEV, C. (2004). Kadim Doğu Edebiyat Tarihi. Bak1.

ORDUBADI, M. S. (1985). Dumanlı Tebriz, I kitab. Bakı: Yazıçı.

ORDUBADI, M. S. (1985). Dumanlı Tebriz, II kitab. Bakı: Yazıçı.

SULTANOV, E. (1866). Seçilmiş Hikâyeler. Bakı. 